\title{
Some Thoughts on Using VR Technology to Communicate Culture
}

\author{
Wangqiao Rong \\ Nanjing Normal University, Nanjing, China \\ Email: 1062643722@qq.com
}

How to cite this paper: Rong, W.Q. (2018) Some Thoughts on Using VR Technology to Communicate Culture. Open Journal of Social Sciences, 6, 88-94.

https://doi.org/10.4236/jss.2018.610008

Received: September 12, 2018

Accepted: October 22, 2018

Published: October 25, 2018

Copyright (C) 2018 by author and Scientific Research Publishing Inc. This work is licensed under the Creative Commons Attribution International License (CC BY 4.0).

http://creativecommons.org/licenses/by/4.0/

\begin{abstract}
VR has the technical characteristics of immersion, interactivity, multi-sense and conceptuality. Its infinity, vividness, network, mobility and cultural diversity, reality, openness, fluidity and diffusivity are highly similar. Therefore, the use of VR technology for cultural communication must be very effective. From the perspective of timeliness and operability, we can start thinking and implementing from the aspects of virtual content, product packaging design, and application environment.
\end{abstract}

\section{Keywords}

VR, Landscape Culture, Classic Literature, Communication

\section{Introduction}

VR (Virtual Reality) is a combination of hardware and software to build a virtual space that allows users to create a sense of immersion in the real world and interact with them. Making full use of this new and popular media is a wonderful way to implant our local culture [1].

\section{Boutique Awareness, Incorporating Excellent Cultural Content into VR}

At present, VR is developing rapidly, but it is basically manifested in the rapid development of hardware, and there is still a prominent problem in software (the so-called content): poor content or rough content. Some VR manufacturers in order to cooperate with the exhibition made a number of virtual content, but in addition to a few more exquisite, wonderful, most of the rough, seriously affecting the overall image of VR products. After all, the core of VR product is virtual content. Without virtual content, VR products have no charm as a body 
without skeleton and skeleton. It is imperative to increase the VR virtual content, especially the development of local excellent culture. The culture of our country has a long history, extensive and profound. How to implant VR technology into Chinese culture and give priority to the culture of our country is a problem worthy of careful study [2]. In view of the current characteristics of VR technology and the level of development, Chinese local culture consumption habits, cognition, and the guidance of national cultural policy can be started from the following aspects.

\subsection{VR Communication of Landscape Culture}

Landscape culture is the crystallization of landscape, landscape and culture. It has a close relationship with philosophy, religion, aesthetics, literature, architecture, sculpture, painting, calligraphy, music and science and technology, so that various cultural phenomena are integrated into one. China's landscape and cultural resources are rich, profound and unique. However, with the continuous development of China's urban construction and the accelerating pace of people's life, the desire to enjoy the Chinese landscape culture on the one hand is becoming more and more intense, on the other hand, it seems to be getting far away from the landscape culture. How to eliminate this embarrassing situation? It is very feasible to use VR to transplant Chinese landscape culture into VR. This is the most common VR virtual tour on the market [3].

Generally speaking, we can start from the following aspects: first, the realistic reproduction of landscape and landscape, such as three mountains and five mountains. This kind of virtual reproduction is not a simple contrast to the simulation of real tourism and tour of the line, but a virtual advantage, which can fully meet the individualized choice of the experiencer. In addition, due to the reasons for personal safety and cultural relics protection, scenic spots and cultural relics that cannot be seen can also be filled with eyes. For example, Lianhua Feng, Tian Du Feng, Dunhuang Mogao Grottoes (Figure 1) in Mount Huangshan,

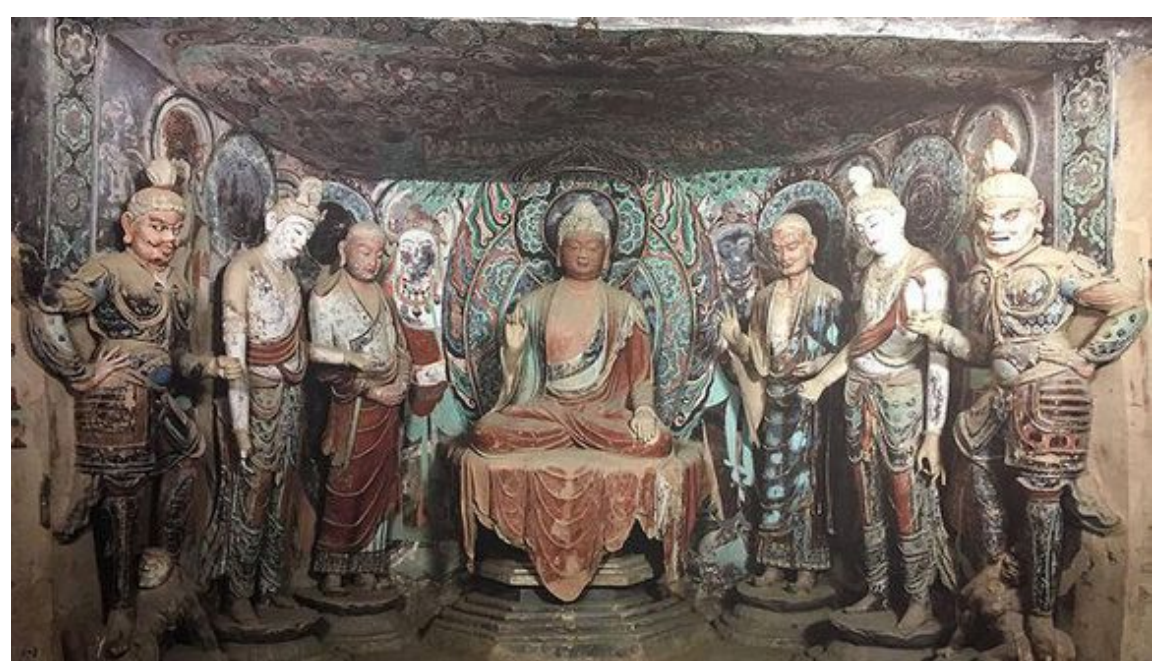

Figure 1. VR roaming of Dunhuang Grottoes. 
etc.. In addition, we should develop the content of VR tour guides, and make a virtual interpretation of the background knowledge of real landscape and cultural relics. The two is the virtual reproduction of the vanished landscape, such as Kroraina and Old Summer Palace. This should be the most meaningful application of the use of VR technology in the excavation of landscape cultural resources. Because of the past and present, because of the war, natural disasters, and other reasons, many historical documents, landscapes, landscapes, buildings have now already disappeared, or only remnant walls, restoration and reconstruction do not have conditions or significance, this time to transport. VR technology for digital reproduction, one can be calculated to make up for shortcomings, two to restore a history, three for Landscape Cultural Relics Tourism add a real content. The three is the legendary landscapes and landscapes, such as Xanadu and the kingdom of the West. These legendary landscapes, landscapes and real landscapes and landscapes are the carriers of landscape culture and part of the whole landscape culture. The use of VR technology, give full play to imagination, the virtual expression of them, one is the completion of the two creation of landscape literature, the two is to complete the landscape literature to the cultural resources of landscape transformation. Four is the illusion of virtual landscapes, such as mirage, heavenly palace, and so on. These imaginary and hallucinatory scenes can also serve as the material of VR virtual tourism. In a word, through the VR virtual tourism experience, we can not only make us fully appreciate the beauty of the motherland, arouse the passion for the motherland, but also effectively disseminating our country's landscape culture, releasing the love of the Chinese nation from ancient times to the nature, and longing for the harmonious relationship with the great nature, and even. We can freely release our association of landscape culture and express our admiration for landscape culture [4].

\subsection{VR Reading of Classic Literature}

Literature is a language art that shapes images and reflects social life with language. It is an important part of culture which has strong appeal. Classical literature in China is a classic work or brilliant work sparkling with brilliant brilliance in the history of Chinese literature. It is a remarkable treasure in the treasure house of world literature. There are many forms of expression in Chinese classical literature, such as poetry, prose, novels, words, Fu and qu. In all kinds of styles, there are many kinds of artistic expression techniques, which make the classical literature of our country have a colorful, magnificent and brilliant picture. Chinese classical literature is the representative of the Chinese national spirit and culture, and it is also a rich resource [5] to develop cultural and creative industries with the effect of Chinese symbols and create material wealth. However, with the popularization of the network, the emergence of the network literature subverts the traditional mode of communication. The network novels have become the new creative subjects outside the mainstream literature, and the 
martial arts, fantasy and romance novels are full of the mobile phone screen of the young people. Many young people talk about the story of Internet novels, and mention classical works. Over time, our classical literature will lose the soil of existence, and the sense of identity of the local excellent culture will be weakened. If we want to reverse this situation as early as possible, we must make use of the forms that young people love to see, such as VR, ingeniously embedding our classical literature [6].

VR can convert the invisible characters of classical literature into authentic and interactive images, which can realize space-time traversing and wandering freely in the scenes depicted in classical literature. For example, the "Romance of the Three Kingdoms" VR game developed by a company is a complete action game of role play. Players will play a member of the Three Kingdoms of Wei, $\mathrm{Shu}$ and $\mathrm{Wu}$. In the game, players use a transmission device to connect the VR helmet with a somatosensory controller to enable the player to experience this audio-visual feast. The game is no longer in the past simple, dramatic story telling, the game scenes, props, character clothing and other portrayal, rendering pretty delicate, exquisite. Through the experience of the VR game, players inadvertently come to the classic master book of the romance of the Three Kingdoms, which are different from the traditional way of reading, not only to have a deeper memory of the plot, but also to leave a more genuine understanding of the clothes, diet, and utensils of the time (Figure 2) [7].

Just imagine, if everyone can interpret classical literature in the way of VR games, who else would not like to join it? Undoubtedly, embedding Chinese classical literature in VR will make it more dazzling.

\subsection{The Integration of Other Characteristic Cultures and VR}

China has a long history, vast territory, large population and great regional difference, so there are many unique traditional culture, such as Wushu, folk custom, medicine, calligraphy, painting, music, sculpture, dance, and so on. After a long period of baptism, these quintessence cultures not only have not atrophied and outdated, but on the contrary, they are thicker, more concise and more

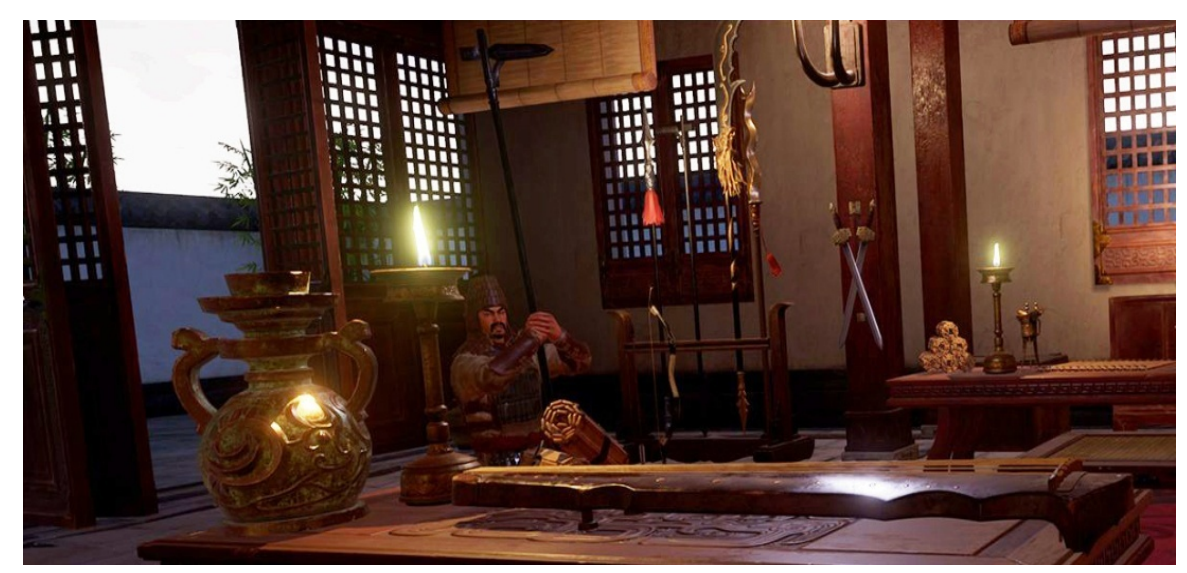

Figure 2. Screenshots of VR games in the romance of the Three Kingdoms. 
consistent with the differences in world culture. Just because they did not get the proper and appropriate publicity, they failed to produce enough influence in the wider range of people and even the whole world. If it can be skillfully implanted into these cultures with the help of VR technology and give full play to the virtual and instantaneous network communication ability of VR's omnipotent digital, it will soon make its value more fully aware. For example, the "Kung Fu Panda with VR", as shown in Figure 3, is a virtual and charmingly naive panda, which can display and teach Chinese Kungfu every time and anywhere. People all over the world follow the practice whenever and anywhere, and feel the profound and profound depth of our Martial Arts in the fun and beneficial entertainment experience [8].

\section{Cultural Communication in VR Product Packaging Design}

\subsection{The Significance of Cultural Communication in Packaging}

The most important thing of cultural marketing is to discover and establish a meeting point between brand and consumer's interaction and sympathy in the mind. Compared with product marketing, this kind of fit point is more indirect and lasting for the purpose and effect of target consumers. The cultural implantation in the packaging design of VR products is an attempt to enhance the connotation of VR products by means of cultural marketing, thus effectively achieving the realization of the value of VR products, and also contributing to the spread of a certain culture.

In addition, with the enhancement of China's national strength and the continuous improvement of international influence, we need to spread and spread China's excellent traditional culture to all parts of the world. VR products, as the most attractive and easily circulated products at present, should spare no effort in packaging design to ingeniously implant the native excellent cultural elements to form the packaging style of VR products with Chinese characteristics and let the world know more quickly and wider to the mainland. China is not only a big manufacturing country, but also a design great and cultural country.

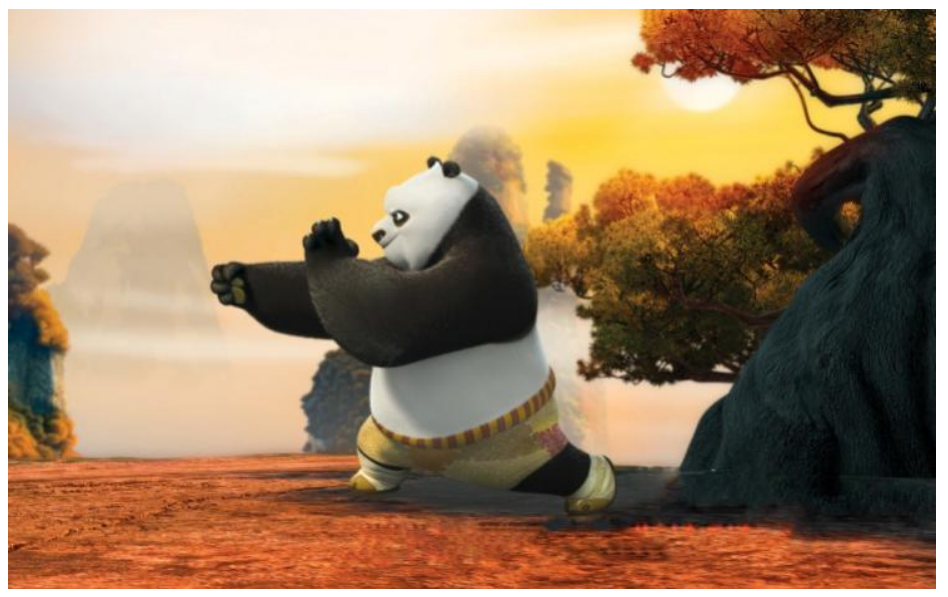

Figure 3. Kung Fu Panda with VR. 


\subsection{The Way of Culture Communication in Packaging}

The cultural quality of VR products is usually reflected in hardware packaging design. China's excellent traditional culture is extensive and profound. It has a profound historical and cultural background. The traditional Chinese traditional elements such as graphics, patterns, patterns, modeling, calligraphy, color and other traditional elements are alive and long, providing the contemporary packaging designers with inexhaustible and useless design materials. In recent years, our country has appeared some excellent packaging design works using Chinese traditional elements for packaging design, such as "Jiugui Liquor", "Wuliangye Liquor" and other wine packaging design, as well as "Yunnan Baiyao Powder", "West Lake Longjing Tea", "Inoherb" and other excellent packaging design. The accumulation of Chinese traditional culture has a great influence on people's aesthetic concept and the molding of values. If these traditional cultural elements are integrated into the packaging design of VR products, the organic implantation of cultural elements in VR products can be realized through the addition and coverage of various cultural elements to produce psychological resonance with the consumers. Then, from the bottom of the heart, it can influence and guide the consumer behavior. At the same time, it also builds a smooth bridge for the communication of some culture [5].

\section{Cultural Communication in VR Experience Environment}

\subsection{The Importance of VR Experience Environment Design}

VR experience environment plays an important role in whether VR products can be experienced. Some people believe that helmet type VR does not have the problem of experiencing environment, because once the experienced person takes the VR helmet, the outside world will not be able to see immediately. People who hold this view may be extremely addicted to VR content and always like to be alone. In fact, this kind of person, and this kind of situation are not common. VR helmet experience usually has a basic experience environment, and in this environment, besides those who are experiencing, there will be people on the sidelines. For the open (in fact, still closed, just out of the helmet) VR experience, it is more necessary to configure the corresponding experience environment, even a large scale of building, indoor and outdoor have a complex design for the VR experience. In a sense, VR equipment and content can only be integrated into the experience environment to fully and completely demonstrate the charm of VR [9].

\subsection{The Basic Idea of Cultural Communication in the Environment}

VR is inseparable from the environment, and the impact of the environment on human beings can be imagined, which provides the soil for the implantation of local culture in the environment. In order to highlight the local cultural characteristics of VR products as far as possible, outdoor to indoor, from music, props 
to light, color design, and so on, can be ingeniously introduced to local cultural elements. Of course, in the process of design, the different types of VR products should be treated differently, and it is more important to keep in harmony with the content and subject of VR. Only in this way can the experiencer really understand and be willing to approach the local culture, understand the local culture and finally accept the local culture [10].

\section{Conflicts of Interest}

The authors declare no conflicts of interest regarding the publication of this paper.

\section{References}

[1] Zhang, Y. (2003) Virtual Epistemology. Tsinghua University Press, Beijing, 98.

[2] Tan, S. and Li, F.X. (2017) The Interrelation of the Value Space of Virtual Reality and Moral Imagination. Social Sciences in Yunnan, No. 3.

[3] Wang, J. and Hu, H.L. (2017) A Few Characteristics of Chinese Cultural Development Based on CCDIS. Journal of Central China Normal University (Humanity), No. 2.

[4] Zheng, G.Q. (2001) Chinese Landscape Culture. Wuhan University Press, Wuhan, 107.

[5] Wang, S. (2009) Creative Expression of the Humanistic Style of Packaging Design. Fine Art Observation, No. 10.

[6] Hu, G.Q. and Ma, L.H. (2017) Application of VR and AR in Wisdom Library. Library Work and Study, No. 9.

[7] Huo, M.C. and Li, H. (2017) Research on the Aesthetic Education Value of "Virtual Reality Game" in the Internet Age. Media, No. 12.

[8] Du, W.M. (2016) Culture China. Peking University Press, Beijing, 107.

[9] Liu, D. (2008) Application of Virtual Reality Technique in Environmental Artistic Design. Journal of Hunan Agricultural University(Natural Sciences), No. 4.

[10] Tian, S.X. (2016) High Technology and Cultural Creativity: Dialogue between Science and Art in the New Media Environment. Journal of Nanjing Arts Institute (Art and Design), No. 5. 